\title{
Survivors of Organizational Change: A Resource Perspective
}

\author{
Yu-Chin Lee, Pei-Chuan Mao \\ ${ }^{1}$ College of Management, I-Shou University, Taiwan \\ Correspondence: Yu-Chin Lee, College of Management, I-Shou University, Taiwan
}

Received: February 26, 2015 Accepted: March 11, 2015 Online Published: March 18, 2015

doi:10.11114/bms.v1i2.692

URL: http://dx.doi.org/10.11114/bms.v1i2.692

\begin{abstract}
The failure rate of organizational change and studies regarding personal turmoil resulting from organizational change indicate that even employees survive layoff, merger, or any forms of changes, they still develop symptoms of distress, cynicism, and work withdrawal. In this paper, we propose a conceptual model based on the conservation of resources theory to examine the effect of organizational change on survivors' organizational identification and well-being. Moreover, we suggest that organizational change may not be as harmful for employees who possess positive attitude toward the process. We offer research propositions and discuss implications for future organizational change research.
\end{abstract}

Keywords: organizational change, organizational identification, employee well-being, conservation of resources theory

\section{Introduction}

Following recent financial crisis and economic downturn, a majority of citizens are being hit by large financial and housing wealth losses, much lower earnings prospects, and elevated uncertainty about job security (International Monetary Fund, 2009). Moreover, many organizations resort to layoffs during periods of financial strain in obvious attempt to reduce personnel costs (Brockner, Grover, Reed, DeWitt \& O'Malley, 1987), such action has worsened the situation and created panicky reaction.

In Taiwan, military organizations operates under such financial strain are forced to adjust manpower structure in order to maintain national combat readiness, further improve the quality of the military personnel, and to better utilize defense resource (National Defense Report [NDR], 2009). Therefore, since year 2004, the national military force started the reengineering process. The organizational structure became fewer levels and the military manpower were reduced from 380,000 people to 275,000 people, reaching a downsize scale of $27.6 \%$. The final goal is to reduce military manpower to 200,000 people by the year 2012 (NDR, 2009).

As these numbers being constantly brought up in the news and governmental report, very few studies have been conducted to examine military personnel's reaction toward such change process. During a reengineering process, it has been claimed that those who remained with the organization shall face even higher amount of stress, uncertainty, and job insecurity than those who have been laid off (Devine, Reay, Stainton \& Collins-Nakai, 2003).

It is therefore, not in the interest of this paper to discuss about the antecedents of organizational change, rather, it is the reactions of those that have gone through prior organizational change process to be the focus of this research. The conservation of resources theory (COR) suggests that people would strive to retain, protect, and build resources when their valuable resources are subject to potential or actual losses (Hobfoll, 1989). By adopting the COR perspective, we propose that, apart from financial resources, the military personnel would also be concerned about losses of organizational identity. The identity survivors used to define themselves with may be wiped out as a result of further cut down, termination of a unit, or transferring to another unit.

However, certain events are stressful only if they are thought to be threats to the physical self or the phenomenological self (Hobfoll, 1989). Therefore, survivors shall not react in the same way. Without digging into the personality and traits factors that would form such bipolar attitude, the conceptual model simply considers an employee's change schema since it is more proximal to this ad hoc event. We propose that despite having harmful effect on survivors' organizational identification and well-being, survivors who possess positive cognitive orientation toward change will be less affected in the process. This paper therefore intends to focus on the survivor-side of story and develops a conceptual model regarding survivors' reactions to organizational change. 


\section{Theoretical Background}

\subsection{Organizational Change and Survivor Reactions}

Reform initiatives have swept through governments everywhere including the United States and emerging economies, again and again bringing news about efforts to reinvent, transform, or reform government agencies (Datta, Guthrie, Basuil \& Pandey, 2010; Fernandez \& Rainey, 2006; Greenglass \& Burke, 2001; Zhou, Tse \& Li, 2006). Organizational change takes several forms such as reorganization of personnel or operations, reduction in force, merger, recapitalization, and so forth (Reilly, Brett, Stroh, 1993). However, those organizations which change is attempted usually fail in their efforts (66\% according to one estimate) or achieve only marginal effects (Sturdy \& Grey, 2003). Hence, vast research has been conducted to find out whether organizations can successfully adapt to changes (Amburgey, Kelly \& Barnett, 1993; Hannan \& Freeman, 1984).

This debate has fall into two streams, one suggests that organizations are relatively malleable, able to adapt when circumstances change (e.g., Thompson, 1967); the other depicted a world of relatively inflexible organizations in which change is both difficult and hazardous (e.g., structural inertia theory, Hannan \& Freeman, 1984). This spectrum of research is prone to structural functionalism and systems theory explanation for organizational change. These streams of research perceive organizational behavior or development to be shaped by a series of impersonal mechanisms that act as external constraints on actors (Astley \& Van de Ven 1983). However, this view has been criticized by the action theorists that organizations are continuously constructed, sustained, and changed by actors' definitions of the situation the subjective meanings and interpretations that actors impute to their worlds as they negotiate and enact their organizational surroundings (Astley \& Van de Ven 1983).

Despite low success rate of organizational change, economic reforms continue usually in forms of mass layoffs (Rama, 1999). The incentives for downsizing involve cost-cutting and pursuance of organizational effectiveness (Freeman, 1994). Yet, organizations should be cautious with consequences of large-scale downsizing, since layoffs have been associated with undesirable consequences, such as turmoil, conflict, lowered morale, job insecurity, distress, and "survivor guilt" (Brockner et al., 1987; Freeman, 1994). In some situations, redesign is likely to follow downsizing when change is forced by the need to accommodate the workload with fewer employees. At this point, stress and work overload are common in these circumstances (Freeman, 1994). These individual reactions can be explained by the conservation of resources (COR) theory (Hobfoll, 1989) which suggests that emotionally exhausted employees tend to protect or replenish their depleting resources by minimizing their efforts to display positive emotions and withdrawing from work (Lam, Huang, \& Janssen, 2010).

Hobfoll (1989) identified four types of resources in the COR model and these include: 1) object resources are valued because of some aspect of their physical nature or because of their acquiring secondary status value based on their rarity and expense; 2) conditions are resources to the extent that they are valued and sought after; 3 ) personal characteristics are resources to the extent that they generally aid stress resistance; and 4) energies are the last resource category and include such resources as time, money, and knowledge. The concept of loss is central to the COR model (Hobfoll, 1989). Examples of object resources can be as small as a deluxe leather chair that is only provided for managers in the company; Marriage, tenure, and seniority are examples of condition resources; personal characteristics usually mean an individual's personal orientation toward the world, seeing events as predictable and generally occurring in one's best interest; and lastly, time, money, and knowledge are illustrations of energy resources.

Following an organizational change, survivors may face changes of job title, job content, workload, work location, or even loss of group members, and find themselves in an awkward position. When survivors first entered the organization, they were socialized in whichever form (i.e., investiture or divestiture socialization tactics) to become committed and loyal employees to the organization or the profession, but when organizational change took place, survivors may have developed the feelings of anger, betrayal, psychological detachment, or loss of identification due to close down of prior operational units.

Those required actions for organizational change facilitation may contribute to role conflict, ambiguity, and alienation of employees, which are antecedents of stress-related outcomes. Moreover, if survivors believe that this turmoil is going to continue, and all the required actions for successful change are harmful to their future development, the implementation of organizational change may evoke unintended responses like denial and resistance, and further result in employees experiencing feelings of stress and cynicism, as well as reduced organizational commitment (Armenakis \& Bedeian, 1999).

Well-being is often discussed in stress models as individual outcomes. It has been revealed that employees working in a high-strain job (high demands-low control) experience the lowest well-being, and control can moderate the negative effects of high demands on well-being (Van der Doef \& Maes, 1999). As originally proposed by Schaufeli and Bakker (2004), there are two dimensions of well-being, burnout and engagement, which are independent of each other. But 
burnout is a negative dimension of well-being, and engagement is positive. However, Schaufeli, Taris, and Van Rhenen (2008) added another dimension to well-being and the validation process again claimed that the newly added dimension (workaholism), burnout, and engagement are three different kinds of employee well-being rather than three of a kind. The definition of workaholism adopted by Schaufeli et al. (2008) is "working excessively hard and the existence of a strong, irresistible inner drive" (p.175). Likewise, workaholics refer to people who tend to allocate an exceptional amount of time to work and they work so hard out of an inner compulsion, need, or drive, not because of external factors such as financial rewards, career perspectives, organizational culture, or poor marriage. This newly added dimension seemed inappropriate for the conceptual model proposed in this paper because organizational change exists as an external force that pushes employees to form some attitude and responds with actions they deemed appropriate. As a result, only burnout and engagement as representations of employee well-being will be discussed.

According to Schaufeli \& Bakker's study (2004), burnout is a metaphor that is commonly used to describe a state of mental weariness. It was originally addressed as an issue in the human services among those who do 'people work' of some kind (Schaufeli \& Bakker, 2004). However, in later research, Leiter and Schaufeli (1996) tested the consistency of the burnout construct across occupations and derived positive result. Gradually, it became obvious that burnout also exists outside the human services. Dimension of burnout includes: a) exhaustion, which measures fatigue without referring to other people as the source of one's tiredness; b) cynicism, which reflects indifference or a distant attitude towards work in general, not necessarily with other people; and c) professional efficacy, which encompasses both social and non-social aspects of occupational accomplishments (MBI-General Survey: Schaufeli, Leiter, Maslach, \& Jackson, 1996). High scores on exhaustion and cynicism, and low scores on professional efficacy, are indicative of burnout.

On the other hand, job engagement is assumed to be the positive antipode of burnout, and it was an attempt to cover the entire spectrum running from employee unwell-being (burnout) to employee well-being (Maslach, Schaufeli, \& Leiter, 2001). Unlike those who suffer from burnout, engaged employees have a sense of energetic and effective connection with their work activities and they see themselves as able to deal well with the demands of their job (Schaufeli et al., 2008). Engagement is characterized by: a) vigor (i.e., high levels of energy and mental resilience while working, the willingness to invest effort in one's work, and persistence also in the face of difficulties); b) dedication (i.e., a sense of significance, enthusiasm, inspiration, pride, and challenge); and c) absorption (i.e., being fully concentrated and engrossed in one's work, whereby time passes quickly and one has difficulties with detaching oneself from work (Schaufeli, Salanova, Gonzalez-Roma. \& Bakker, 2002).

Therefore, we anticipate that survivors' organizational identification is likely to be threatened and they will experience lower level of well-being due to the changes.

Proposition 1a: Organizational change will be negatively related to survivors' organizational identification.

Proposition 1b: Organizational change will be negatively related to survivors' well-being.

However, if a personal has a broad resource pool, then he or she is more likely to successfully break the cycle of loss spiral (Hobfoll, 2001). In the next section, we will explicate on the moderating effect of change schema on the relationship between organizational change and survivors' organizational identification and well-being.

\subsection{The Moderating Effect of Change Schema}

Studies observed in a review article suggested that when an individual's self-interest is being threatened, a proposed change is likely to prompt resistance (Armenakis \& Bedeian, 1999). This contention resembles the supposition of COR theory which links burnout to a net loss, or fear of loss, of valued resources (Hobfoll, 1989; Neveu, 2007). Hence, if the survivors' cognitive map toward change is mostly negative, then, as suggested by past research, the implementation of organizational change is unlikely to succeed due to negative individual outcomes. In contrast, if survivors' think favorably toward the change, the whole story should look differently.

Change schema refers to the attitude of people in an organization towards changes (Lau, Tse, \& Zhou, 2002). It is developed from the idea of cognitive map that involves the attributes of change events and the relationships among these events; therefore, it is context-specific (Walsh, 1995). Lau et al. (2002) operationalized the construct with three dimensions including change attributes (salience), affect towards change (valence) and perceived consequence of change (inference). The change salience dimension involves a cognitive element of affirming the need to and significance of change, seeking more information, and the willingness to help out changes; change valence represents an understanding of the benefits of change and reform and hence the confidence and commitment to change; and change inference describes the evaluation and concerns one has over the change event (Lau et al., 2002).

When survivors have a strong belief in the necessity of change, supportive mindset toward change, and positive appraisal of the result, then the danger or threats of lost identification to oneself is mitigated, and the survivors will be more likely to invest vigor and dedication in the job. In the contrary, if the employees possess negative attitude or 
cognitive map toward organizational change, it is likely that employees will anticipate large chunk of workload, lack of resources, and few organizational support. Hence,

Proposition 2: Survivors' change schema will mitigate the negative effect of organizational change on survivors' organizational identification and well-being.

\section{Discussion}

Receptivity, resistance, commitment, cynicism, stress, and related personal reactions are clearly relevant criterion variables to be considered in the framework of planning and implementing an organizational change (Armenakis \& Bedeian, 1999). Although there are various ways to define what is a successful change outcome, when it comes to management of employees, their physical and psychological well-beings are always the main concern. In line with the supposition of COR theory, it is implied that organizational change may serve as a threat to individuals, despite prior levels of organizational identification, individuals may develop stress-related symptoms such as burnout. As the authors aware of, there have not been any studies conducted to examine the positive dimension of well-being on employees who have gone through organizational change. While most scholars are concerned about the 'dehumanized' organizational change strategy, it may be worthwhile to look for bright-side features of employees.

\section{Implications for Future Research}

What is critical for organizations is knowing how to help exhausted employees recover from resources depletion and maintain positive emotional display (Tice, Baumeister, Shmueli, \& Muraven, 2007). A workplace filled with distressful individuals will not do any good to the change process. Even for organizations that have over hundreds of employees, size does not necessarily promise for job security. Certainly, the employees may feel proud to be identified with the organization, but when it comes to turbulent times, some humanized actions (e.g., direct communication) would really do help the employees to know what to expect for and to believe in the actions of organization, and devote themselves to the organization instead of spending working hours on job hunting. Employees need assurance or at least enough information about the change process to form a positive attitude toward the organizational change. The conceptual model proposed here suggests a possibility that once employees approve of the change about to come, organizations will face less resistance and succeed in the process.

\section{References}

Amburgey, T. L., Kelly, D., \& Barnett, W. P. (1993). Resetting the clock: The dynamics of organizational change and failure. Administrative Science Quarterly, 38, 51-73. http://dx.doi.org/10.5465/AMBPP.1990.4978494

Armenakis, A. A., \& Bedeian, A. G. (1999). Organizational change: A review of theory and research in the 1990s. Journal of Management, 25, 293-315. http://dx.doi.org/10.1177/014920639902500303

Ashforth, B. E., \& Mael, F. (1989). Social identity theory and the organization. Academy of Management Review, 14, 20-39. http://dx.doi.org/10.5465/AMR.1989.4278999

Astley, W., \& Van de Ven, A. (1983). Central perspectives and debates in organization theory. Administrative Science Quarterly, 28, 245-273.

Brockner, J., Grover, S., Reed, T., DeWitt, R., \& O'Malley, M. (1987). Survivors' reactions to layoffs: We get by with a little help for our friends. Administrative Science Quarterly, 32, 526-541.

Datta, D. K., Guthrie, J. P., Basuil, D., \& Pandey, A. (2010). Causes and effects of employee downsizing: A review and synthesis. Journal of Management, 36, 281-348. http://dx.doi.org/10.1177/0149206309346735

Devine, K., Reay, T., Stainton, L., \& Collins-Nakai, R. (2003). Downsizing outcomes: Better a victim than a survivor? Human Resource Management, 42, 109-124. http://dx.doi.org/10.1002/hrm.10071

Fernandez, S., \& Rainey, H. G. (2006). Managing successful organizational change in the public sector. Public Administration Review, 66, 168-176. http://dx.doi.org/10.1111/j.1540-6210.2006.00570.x

Freeman, S. (1994). Organizational downsizing as convergence or reorientation: Implications for human resource management. Human Resource Management, 33, 213-238. http://dx.doi.org/10.1002/hrm.3930330205

Greenglass, E. R., \& Burke, R. J. (2001). Editorial introduction downsizing and restructuring: Implications for stress and anxiety. Anxiety, Stress, and Coping, 14, 1-13. http://dx.doi.org/10.1080/10615800108248345

Hannan, M. T., \& Freeman, J. (1984). Structural inertia and organizational change. American Sociological Review, 49, 149-164.

Hobfoll, S. E. (1989). Conservation of resources: A new attempt at conceptualizing stress. American Psychologist, 44, 513-524.

Hobfoll, S. E. (2001). The influence of culture, community, and the nested-self in the stress process: Advancing 
conservation of resources theory. Applied Psychology: An International Review, 50, 337-421. http://dx.doi.org/10.1111/1464-0597.00062

International Monetary Fund. (2009). World economic outlook April 2009: Crisis and recovery. International Monetary Fund.

Lam, C. K., Huang, X., \& Janssen, O. (2010). Contextualizing emotional exhaustion and positive emotional display: The signaling effects of supervisors' emotional exhaustion and service climate. Journal of Applied Psychology, 95, 368-376. http://dx.doi.org/10.1037/a0017869

Lau, C., Tse, D. K., \& Zhou, N. (2002). Institutional forces and organizational culture in China: Effects on change schemas, firm commitment and job satisfaction. Journal of International Business Studies, 33, 533-550. http://dx.doi.org/10.1057/palgrave.jibs.8491030

Leiter, M. P., \& Schaufeli, W. B. (1996). Consistency of the burnout construct across occupations. Anxiety, Stress, and Coping, 9, 229-243. http://dx.doi.org/10.1080/10615809608249404

Mael, F., \& Ashforth, B. E. (1992). Alumni and their alma mater: A partial test of the reformulated model of organizational identification. Journal of Organizational Behavior, 13, 103-123. http://dx.doi.org/10.1002/job.4030130202

Maslach, C., Schaufeli, W. B., \& Leiter, M. P. (2001). Job burnout. Annual Review of Psychology, 52, 397-422. http://dx.doi.org/10.1146/annurev.psych.52.1.397

Ministry of National Defense. (2009). 2009 National Defense Report: The Republic of China. Ministry of National Defense.

Neveu, J. (2007). Jailed resources: Conservation of resources theory as applied to burnout among prison guards. Journal of Organizational Behavior, 28, 21-42. http://dx.doi.org/10.1002/job.393

Rama, M. (1999). Public sector downsizing: An introduction. The World Bank Economic Review, 13, 1-221. http://dx.doi.org/10.1093/wber/13.1.1

Reilly, A. H., Brett, J. M., \& Stroh, L. K. (1993). The impact of corporate turbulence on managers' attitudes. Strategic Management Journal, 14, 167-179. http://dx.doi.org/10.1002/smj.4250140913

Schaufeli, W. B., \& Bakker, A. B. (2004). Job demands, job resources, and their relationship with burnout and engagement: A multi-sample study. Journal of Organizational Behavior, 25, 293-315. http://dx.doi.org/10.1002/job.248

Schaufeli, W. B., Leiter, M. P., Maslach, C., \& Jackson, S. E. (1996). Maslach Burnout Inventory-General Survey. In C. Maslach, S. E. Jackson, \& M. P. Leiter (Eds.), The Maslach Burnout Inventory: Test manual (pp.22-26). Consulting Psychologists Press. http://dx.doi.org/

Schaufeli, W. B., Salanova, M., Gonzalez-Roma. V., \& Bakker, A. B. (2002). The measurement of engagement and burnout: A confirmatory factor analytic approach. Journal of Happiness Studies, 3, 71-92. http://dx.doi.org/10.1023/A:1015630930326

Schaufeli, W. B., Taris, T. W., \& Van Rhenen, W. (2008). Workaholism, burnout, and work engagement: Three of a kind or three differend kinds of employee well-being? Applied Psychology: An Internatioanl Review, 57, 173-203. http://dx.doi.org/10.1111/j.1464-0597.2007.00285.x

Sturdy, A., \& Christopher, G. (2003). Beneath and beyond organizational change management: Exploring alternatives. Organization, 10, 651-662. http://dx.doi.org/10.1177/13505084030104006

Thompson, J. D. (1967). Organizations in Action. McGraw-Hill.

Tice, D. M., Baumeister, R. F., Shmueli, D., \& Muraven, M. (2007). Restoring the self: Positive affect helps improve self-regulation following ego depletion. Journal of Experimental Social Psychology, 43, 379-384. http://dx.doi.org/10.1016/j.jcps.2007.10.002

Van der Doef, M., \& Maes, S. (1999). The job demand-control(-support) model and psychological well-being: A review of 20 years of empirical research. Work \& Stress, 13, 87-114. http://dx.doi.org/10.1080/026783799296084

Walsh, J. P. (1995). Managerial and organizational cognition: Notes from a trip down memory lane. Organization Science, 6, 280-321. http://dx.doi.org/10.1287/orsc.6.3.280

Zhou, K. Z., Tse, D. K., \& Li, J. J. (2006). Organizational changes in emerging economies: Drivers and consequences. Journal of International Business Studies, 37, 248-263. http://dx.doi.org/10.1057/palgrave.jibs.8400186

\section{(cc) $\mathrm{BY}$}

This work is licensed under a Creative Commons Attribution 3.0 License. 